ASIAN JOURNAL OF MANAGEMENT STUDIES

Journal homepage: https://www.sab.ac.lk/ajms/

\title{
Book Review: Towards A Common Future: Understanding Growth, Sustainability in the Asia-Pacific Region edited by Banik, A., Barai, M. K. and Suzuki, Y. (Palgrave Macmillan; $1^{\text {st }}$ Edition (2017), Pages: 366)
}

\section{MK Wanniarachchige}

Department of Accounting and Finance, Faculty of Management and Finance, University of Ruhuna, Sri Lanka

Asia-Pacific Region, which constitutes of a wide geographic spread and a substantially large landmass, accounting for around one-fifth of the world's landmass, houses more than half of the world population. The countries in the region are uniquely characterised by diverse socio-political aspects and with various stages of economic development. Resurgence in economic power in the Asia-Pacific Region is evident and well documented in the literature. A closer look at the region, however, reveals a number of challenges that has the potential to impose serious threats to the future growth of the region, particularly in its quest for sustainable development. Moreover, a series of economic and political conditions pertaining to countries like China, India, South Korea, and North Korea has raised concerns on global peace, highlighting the extent of global attention in the region.

(C) Faculty of

Management Studies

Sabaragamuwa

University of Sri Lanka

ARTICLE INFO

Article history:

Received: 10 January 2021

Accepted: 24 January 2021

Published: 09 February 2021

E-mail Address:

manjula@mgt.ruh.ac.lk 
This book titled "Towards A Common Future: Understanding Growth, Sustainability in the Asia-Pacific Region" edited by three eminent scholars, namely, Arindam Banik, Munim Kumar Barai, and Yasushi Suzuki, touches upon the challenge of attaining "a common future of sustainable development" in the region through addressing several key issues ranging from economic prosperity to environmental sustainability. To this end, the book sheds light on unique conditions and some of the salient endeavours initiated both individually and cooperatively by some of the countries in ensuring regional wellbeing and its integration with the rest of the world. The book contains seventeen chapters meticulously arranged into seven parts, each focusing on a focal point in the region.

Chapter 1 of Part I presents a comprehensive overview of the AsiaPacific Region, encompassing the rationale behind recognising this particular landmass as a region, its geographical reach, the status of economic development in various countries in the region, and some of the key initiatives that have been initiated in the region targeting economic development and regional cooperation. This discussion signals the historical shift of social and economic powers from the Asia-Pacific Region to the West-European Region and then, recently, back to Asia-Pacific Region. The authors then provide a well-thought classification for the countries in the region depending on the status of their economic and social development. For example, China, Japan, and India have been identified as countries with global ambition, while emerging economies like South Korea, Thailand and Vietnam have been recognised as countries that can continue to aspire the global recognition they have achieved so far, though they still lag behind aforementioned countries. Concurrently, another layer of countries trying to catch up with the economic growth has been recognised.

Nonetheless, the authors have identified economic growth, social development, modernisation, a sustainable environment, and peace as some of the common goals for the countries in the region. Simultaneously, political relations among countries that are tightly connected with historical experiences, asymmetric sub-regional development, issues pertaining to the controlling power of the sea routes in the South China sea, interventions of external powers like the USA, competition for power within the region, and the lack of common economic and political platforms have been identified as the key challenges facing the region as a whole, as well as where individual countries are concerned. This nearly encompasses a greater part of the topics 
that can be contemplated in relation to regional development and sustainability. As a whole, the discussion in this chapter highlights the AsiaPacific Region in a noteworthy perspective, portraying the unique as well as the common challenges facing each country and lays the foundation for the rest of the discussion.

Part II focuses on China, the Asian giant largely characterised by Marxian social ideology even to date. Here, in Chapter 2, Suzuki and Miah blend the views of institutional economics and political economics to elaborate the resurgence of China in terms of economic power. Beyond this, the authors document a set of necessary conditions for China to move forward without falling into the so-called middle-income trap in the backdrop of economic slowdown followed by US financial crisis. They also shed light on the key challenges facing China in doing so. Closely aligned with the arguments of Suzuki, Miah and Jiang, in Chapter 3, documents the evidences pertaining to unbalanced and unequal development in China in a way to show how the various economic and social reforms have failed to instil satisfactory social development despite its enormous economic prosperity. Chapter 4 is mainly written on the "Belt and Road" initiative put forward by China aimed at strengthening the economic integration of Asia with the European region. In this chapter, Wong conceptually analyses the potential economic impacts of the proposed "Belt and Road" initiative, providing an immense optimism towards a stronger economic integration between the Asia-Pacific Region and the rest of the world.

Part III is centred on the role that India can play as the leading economy in the relatively disintegrated South Asian sub-region. To this end, Chapter 5, while providing evidences for sub-regional disparities in Asia, urges the economies to focus on sub-regional integration as the first step in achieving a common future. Here Mukherjee, highlights the role the countries like China and India would have to play in bridging the economic integration of South Asia particularly, since this sub-region is lagging far behind the economic integration between East Asia and South-East Asia. In this context, Chapter 6 documents the role that Micro and SMEs are playing and the challenges they are facing in terms of innovativeness of the business model, expansion of knowledge base, infrastructure development, and institutional support in contributing to regional integration and sustainable development. In Chapter 7, Kaul explores a set of industries in India to claim the creation of shared values as a vital step in ensuring social justice and a sustainable future. These 
discussions partially address the reason why the South Asian region lags behind in economic integration relative to the other sub-regions.

Part IV provides a comparative view on the relations among Japan, China, and India. For example, Chowdhury in Chapter 8 shows how India has recorded remarkable growth since the 1990s in parallel with the time period when the Japanese economy has encountered the worst economic downturn subsequent to its high growth period. Though these distinct economies can be hardly compared, the author documents few striking complementarities between Japan and India that may well be capitalised on to enhance the economic integration between the two countries. Adding to this discussion, Suzuki and Kar, in Chapter 9, provide a plausible explanation on why the innovation might have been curtailed in India by referring to the drivers of economic growth in India and the potential factors that might have prevented Japan from entering into closer economic ties with India. Then, slightly shifting the focus, Chapter 10 pays attention to the two Asian giants where Barai provides an extensive discussion on the economic integration between Japan and China to claim that the two countries need each other for economic prosperity. The discussions in these three chapters plot Japan, China, and India as three contesting and complementary centres of economic power in the AsiaPacific Region.

In Part V of the book, Chapter 11 discusses how Korea, as a catching up economy which recently remains relatively stagnant compared to major Asian economies like Japan and China, should respond to the emerging trends and challenges in the Asia-Pacific Region as well as in the globe. In Chapter 12, adding a unique perspective to the discussions in the book, Moosa claims that the potential ill effects of economic growth can be mitigated through carefully drafted environmental regulations. This argument seems quite plausible in relation to economies with well-developed institutions, whereas why such environmental regulations have not been formulated in other economies remains a crucial question that is yet to be answered. In Chapter 13, Adams, taking Taiwan as a case, provides further evidence from an institutional as well as from a political perspective for the existence of major political issues of regional importance in Taiwan. Parallelly, Chapter 14 draws the attention on the deindustrialisation as one of the potential causes for Indonesian currency depreciation. The arguments presented in this chapter seem to be applicable in many other Asian economies suffering from continuous depreciation of domestic currency. 
Part VI touches upon trade and economic cooperation initiatives in the Asia-Pacific region. For example, Chapter 15 provides a comprehensive snapshot of the transformations taking place in the Asia-Pacific Region while addressing some of the issues pertaining to why some of the countries are locked in underdeveloped status for a long period despite their resourcefulness. Here, the author draws heavily upon the Trans-Pacific Partnership and Asia-Pacific Economic Cooperation initiatives. While extending this discussion, Chapter 16 presents the role of the Asian Infrastructure Investment Bank in promoting infrastructure investments needed for regional cooperation, sustainable growth, and particularly in reducing the reliance of the Asian countries on investment from Western countries.

Finally, under Chapter 17 in Part VII, Barai and Banik conclude the discussion by envisioning a brighter future in Asia-Pacific Region, probably making the 21st Century an "Asia-Pacific Century" while highlighting the challenges the countries in Asia-Pacific Region have to face in their way forward. As a whole, this book brings forward a variety of closely connected and complementary arguments pertaining to the economic integration and development of the Asia-Pacific Region. Further, the book is fairly balanced in terms of its theoretical discourse and empirical support. An inspiring blend of the perspectives from institutional economics and political economics throughout the discussions is also noteworthy. This unique composition, which facilitates the reader to grasp a variety of economic as well as political underpinnings in the Asia-Pacific Region, makes this a book worthy of reading. 